\title{
Factors of interrupting chemotherapy in patients with Advanced Non-Small-Cell Lung Cancer
}

\author{
Rhizlane Belbaraka*1,2, Olivier Trédan'1, Isabelle Ray-Coquard1', Giselle Chvetzoff1', Agathe Bajard³, David Pérol', \\ Nabil Ismaili2, Mohammed Ismaili4', Hassan Errihani2 ${ }^{2}$ Thomas Bachelot ${ }^{1}$ and Paul Rebattu'
}

\begin{abstract}
Background: Little is known about prognosis of metastatic patients after receiving a first-line treatment and failure. Our group already showed in pre-treated patients enrolled in phase I clinical trials that a performance status (PS) $>2$ and an $\mathrm{LDH}>600 \mathrm{UI} / \mathrm{L}$ were independent prognostic factors. In this prospective study, which included 45 patients, we identified clinical and biological variables as outcome predictors in metastatic Non-Small Cell lung cancer after first line chemotherapy were identified.

Findings: Forty-five patients that were previously treated for metastatic disease from 12/2000 to 11/2005 in the comprehensive cancer centre (Centre Léon Bérard). Clinical assessment and blood parameters were recorded and considered. Patient prognostic factors for overall survival (OS) with a 0.05-significance level in univariate analysis were entered in a multivariate Cox model for further analysis.

Patients' median age was 58.5 years (range: 37 - 76). Sixty two percent of the patients were PS $=0$ or 1. After inclusion, nine patients received second-line (22.5\%), and two received third-line chemotherapy (5\%). Univariate analysis showed that the factors associated with reduced OS were: PS $>2$, weight loss $>10 \%$, more than one line of chemotherapy treatment and abnormal blood parameters (hemoglobin $(\mathrm{Hb})$, platelet and neutrophils counts). Multiple regression analysis confirmed that PS > 2 and abnormal hemoglobin were independent predictors for low overall survival. According to the presence of none (33\%), 1 (37\%) and 2 (30\%) prognostic factors, median OS were 12,5 and 2 months respectively.

Conclusion: From this prospective study, both PS and anemia were found as independent determinants of survival, we found that both PS and anemia were independent determinants of survival. The combination of poor PS and anemia is an effective strategy to predict survival in the case of patients with metastatic NSCLC receiving further treatment after the first line.
\end{abstract}

\section{Findings}

Prediction of survival in the case of advanced non-small cell lung cancer (NSCLC), when patients have already received first line treatment, is critical to the decision of subsequent treatments. Defining prognostic determinants of NSCLC may help physicians to improve their decisions making for both clinical trials and routine practice [1].

Many studies have reported predictive models for survival in metastatic cancers. These models integrated a

* Correspondence: r_belbaraka@yahoo.fr

1 Department of Medical Oncology, Centre Léon-Bérard, 28 Rue Laennec, Lyon69008, France

Full list of author information is available at the end of the article combination of clinical and biological factors. Biological characteristics such as lactate dehydrogenase level (LDH) [4], lymphocyte count [2,3], or Interleukin 6 level [5,6] have been correlated with poor outcome in metastatic cancer.

In this study, we aimed to identify clinical and biological variables as outcome predictors for early death in locally advanced or metastatic NSCLC in patients treated beyond the first line chemotherapy failure.

\section{Patients and methods}

The investigation was a prospective, observational, single-centre study. 
Inclusion criteria were: patients $>18$ years old with locally Advanced or metastatic NSCLC who were eligible for further chemotherapy after first line chemotherapy failure.

Exclusion criteria were: new patients who had not yet received any chemotherapy.

Written consent was obtained from each patient. The institutional ethics committee approved the study protocol before implementation, on March 17, 2000.

The primary objective of this study was to identify clinical and biological variables as prognostic factors for metastatic NSCLC patients after failure of first line chemotherapy.

These variables were collected at inclusion: age, gender, Eastern Cooperative Oncology Group (ECOG) PS, weight loss, number and sites of metastases, previous and current chemotherapy regimens. In addition to laboratory tests which included complete blood accounts (hemoglobin, neutrophils, lymphocytes), albumin, LDH and C-reactive protein (CRP) levels. According to our previous studies, the cutoff of each biological parameter was defined as follows: the albumin level $+/-38 \mathrm{~g} / \mathrm{l}$, the lymphocytes count $+/-700 \mu \mathrm{L}[2,3]$, the LDH level +/$600 \mathrm{U} / \mathrm{L}$ [4] , and anemia was defined as hemoglobin level $(\mathrm{Hb})$ less than $11.5 \mathrm{~g} / \mathrm{dL}$ for female and less than $13.0 \mathrm{~g} /$ dL for male.

\section{Statistical considerations}

Survival analysis: the primary outcome was overall survival, defined as the time from inclusion to death or to last follow-up. Survival distributions in prognostic groups were estimated by the Kaplan-Meier method.

Univariate and multivariate analysis: to evaluate the relationship between survival and baseline characteristics, all clinical and biological variables were included in univariate Cox proportional hazard regression models. The log-rank test was used to compare survival curves. Candidate prognostic factors for overall survival with a 0.05 level of significance in univariate analysis were entered in a multivariate Cox model.

\section{Results}

\section{Patients' characteristics (Table 1)}

Between 2000 and 2005, 45 patients with metastatic NSCLC were included in the study. Their characteristics are summarized in table 1 . Thirty patients were male $(75 \%)$ and fifteen female (25\%). Median age was 58.5 years (range 37-76). Sixty two percent had PS $0-1$. Only 6 patients $(14 \%)$ had a weight loss of $10 \%$ or more in the previous six months.

All patients received platinum based first line chemotherapy. Prior to inclusion, 9 patients received second line treatment and two patients received third line chemo-
Table 1: Patients' characteristics

\begin{tabular}{|c|c|}
\hline Patients Characteristics & Number (Percent) \\
\hline Total & $45(100)$ \\
\hline \multicolumn{2}{|l|}{ Age, years } \\
\hline Median & 58.5 \\
\hline Range & $34.7-76.9$ \\
\hline \multicolumn{2}{|l|}{ Gender } \\
\hline Male & $30(66.7)$ \\
\hline Female & $15(33.3)$ \\
\hline \multicolumn{2}{|l|}{ ECOG Performance Status } \\
\hline \multicolumn{2}{|l|}{ Assessed by the physician } \\
\hline 0 & $4(9.3)$ \\
\hline 1 & $23(53.5)$ \\
\hline$>1$ & $16(37.2)$ \\
\hline \multicolumn{2}{|l|}{$\begin{array}{l}\text { Self-assessed by the } \\
\text { patient }\end{array}$} \\
\hline 0 & $0(0.0)$ \\
\hline 1 & $17(37.8)$ \\
\hline$>1$ & $28(62.2)$ \\
\hline Weight loss $>10 \%$ & $6(14.0)$ \\
\hline \multicolumn{2}{|l|}{ Number of metastases } \\
\hline 1 & $8(18.2)$ \\
\hline 2 & $21(47.7)$ \\
\hline$>2$ & $15(34.1)$ \\
\hline \multicolumn{2}{|l|}{ Site of metastases } \\
\hline Bone & $11(24.4)$ \\
\hline Liver & $14(31.1)$ \\
\hline Lung & $28(62.2)$ \\
\hline Brain & $12(26.7)$ \\
\hline \multicolumn{2}{|l|}{ Previous treatment } \\
\hline Adjuvant chemotherapy & $4(8.9)$ \\
\hline \multicolumn{2}{|l|}{ Treatment completed } \\
\hline First-line & $29(72.5)$ \\
\hline Second-line & $9(22.5)$ \\
\hline$>$ Second-line & $2(5.0)$ \\
\hline \multicolumn{2}{|l|}{ Treatment after inclusion } \\
\hline Palliative chemotherapy & $45(100.0)$ \\
\hline
\end{tabular}


therapy treatment (single agent Docetaxel or Gemcitabine).

Biological variables are summarized in Table 2. All laboratory data were available for all patients. Majority of the patients presented anemia (65\%), low albumin level (77.5\%) and high CRP level (54\%).

\section{Survival}

Because almost all patients died (42/45), the KaplanMeier method have not been used to calculate the follow-

\section{Table 2: Biological tests}

\begin{tabular}{|c|c|}
\hline Parameters & Number (Percent) \\
\hline \multicolumn{2}{|l|}{ Hemoglobin } \\
\hline $\begin{array}{l}\text { Abnormal }(<11.5 \mathrm{~g} / \mathrm{dL} \\
\text { for female; }<13.0 \mathrm{~g} / \mathrm{dL} \\
\text { for male) }\end{array}$ & $29(64.4)$ \\
\hline \multicolumn{2}{|l|}{ Absolute Neutrophil Count } \\
\hline$<2000 / \mu \mathrm{L}$ & $1(2.2)$ \\
\hline $2000-7500 / \mu \mathrm{L}$ & $31(68.9)$ \\
\hline$>7500 / \mu \mathrm{L}$ & $13(28.9)$ \\
\hline \multicolumn{2}{|l|}{ Lymphocyte count } \\
\hline$<700 / \mu \mathrm{L}$ & $20(46.5)$ \\
\hline $700-1000 / \mu \mathrm{L}$ & $10(23.3)$ \\
\hline$\geq 1000 / \mu \mathrm{L}$ & $13(30.2)$ \\
\hline Missing data & 2 \\
\hline \multicolumn{2}{|l|}{ Platelet count } \\
\hline$<130 \mathrm{G} / \mathrm{L}$ & $5(11.1)$ \\
\hline $130-400 \mathrm{G} / \mathrm{L}$ & $33(73.3)$ \\
\hline$>400 \mathrm{G} / \mathrm{L}$ & $7(15.6)$ \\
\hline \multicolumn{2}{|l|}{ Albumin } \\
\hline$<38 \mathrm{~g} / \mathrm{L}$ & $31(77.5)$ \\
\hline Missing data & 5 \\
\hline \multicolumn{2}{|l|}{ LDH } \\
\hline$>600 \mathrm{U} / \mathrm{L}$ & $10(27.0)$ \\
\hline Missing data & 8 \\
\hline \multicolumn{2}{|l|}{ CRP } \\
\hline$\leq 10 \mathrm{mg} / \mathrm{L}$ & $15(45.5)$ \\
\hline $10-50 \mathrm{mg} / \mathrm{L}$ & $8(24.2)$ \\
\hline$>50 \mathrm{mg} / \mathrm{L}$ & $10(30.3)$ \\
\hline Missing data & 12 \\
\hline
\end{tabular}

LDH: lactate dehydrogenase; CRP: C-reactive protein; up. To estimate it, we provide the median of the delays of survival for all patients, which was 3.1 months (range: 0.2 - 46.7 months).

Univariate analysis showed that six variables were correlated with poor outcome $(\mathrm{p}<0.05)$.

As clinical parameters, we found PS $>1$, weight loss $(<10 \%)$ and more than one line of chemotherapy treatment. Anemia, platelet level $<130000$ and IL6 $>8$ pg $/ \mathrm{ml}$ were also associated with poor clinical outcome. Table 3 summarized results of prognostic parameters using univariate and multivariate analysis.

Multivariate analysis showed that only two variables were statistically correlated with significant poor prognosis $(\mathrm{p}<0.05)$ : PS $>1$ and anemia. Figures 1 and 2 showed the relationship between PS or $\mathrm{Hb}$ level and overall survival. The median survival was 2 months when PS $>1$ versus 8 months when PS: $0-1$. The median survival was 3 months when $\mathrm{Hb}$ level was abnormal versus 9 months when $\mathrm{Hb}$ level was normal.

We can then define 4 groups of survival. Figure 3 show the results of the analysis of 0,1 or 2 prognostic factors with Kaplan-Meier overall survival analysis. Group1 (13 patients) was a poor outcome group with only 1.9 months median survival (CI95: 0.9-2.3) and had a PS $>1$ and anemia.

Group 2 (13 patients) was a good outcome group with 12.1 months median survival (CI95: $3.1-26.4$ ) and had a PS: 0-1 and normal $\mathrm{Hb}$.

In addition, two intermediate groups were identified: one with a PS $>1$ and normal $\mathrm{Hb}$ (3 patients) and had a median survival of 2.6 months (CI95: 2.3-NA), and a second with a PS: $0-1$ and anemia (14 patients) and had a median survival of 5.3 months (CI95: 2.5-6.4).

\section{Discussion}

From this prospective study, we found that both PS and anemia were independent prognostic factors of survival for metastatic NSCLC patients who relapsed after the first line chemotherapy. The combination of poor PS and anemia is an effective strategy to predict survival and then to select patients who may be will not benefit from further chemotherapy.

Up till now, most widely accepted prognostic determinants are disease stage and performance status [8]. Many large trials considered other features such as male gender, age older than 60 years, non-squamous histologics, weight loss as stratification factors insofar as they have been reported as negative prognostic factors [9].

As in other types of cancer, PS plays a clear prognostic role in advanced NSCLC. In all the retrospective and prospective trials regarding prognostic factors in this disease, PS has been shown to be an independent prognostic parameter [10]. 
Table 3: Prognostic parameters on univariate and multivariate analysis for lung cancer patients

\begin{tabular}{|c|c|c|c|c|c|c|}
\hline & \multicolumn{3}{|c|}{ Univariate analysis } & \multicolumn{3}{|c|}{ Multivariate analysis } \\
\hline & HR & $95 \% \mathrm{Cl}$ & $\mathbf{p}$ & HR & $95 \% \mathrm{Cl}$ & $\mathbf{p}$ \\
\hline \multicolumn{7}{|c|}{ ECOG Performance Status assessed by the physician } \\
\hline $\begin{array}{l}0-1 \\
>1\end{array}$ & 3.641 & {$[1.743-7.607]$} & 0.0006 & 3.279 & [1.546-6.955] & 0.0020 \\
\hline \multicolumn{7}{|c|}{ Hemoglobin } \\
\hline $\begin{array}{l}\text { Normal } \\
\text { Abnormal }\end{array}$ & 2.941 & {$[1.401-6.172]$} & 0.0044 & 2.781 & {$[1.290-5.997]$} & 0.0091 \\
\hline \multicolumn{7}{|c|}{ Platelet count (G/L) } \\
\hline $\begin{array}{l}\geq 130 \\
<130\end{array}$ & 4.023 & [1.512-10.703] & 0.0053 & & & NS \\
\hline \multicolumn{7}{|c|}{ Weight loss > $10 \%$} \\
\hline $\begin{array}{l}\text { No } \\
\text { Yes }\end{array}$ & 2.633 & {$[1.079-6.423]$} & 0.0334 & & & NS \\
\hline \multicolumn{7}{|c|}{ Number of metastases } \\
\hline $\begin{array}{l}\leq 2 \\
>2\end{array}$ & 1.776 & {$[0.913-3.453]$} & 0.0904 & & & NS \\
\hline \multicolumn{7}{|c|}{ Number of chemotherapy lines } \\
\hline $\begin{array}{l}\leq 1 \\
>1\end{array}$ & & & 0.0305 & & & NS \\
\hline \multicolumn{7}{|c|}{ Albumin (g/L) } \\
\hline $\begin{array}{l}\geq 38 \\
<38\end{array}$ & 1.585 & [0.722-3.481] & 0.2510 & & & - \\
\hline \multicolumn{7}{|c|}{ CRP (mg/L) } \\
\hline $\begin{array}{l}\leq 10 \\
>10\end{array}$ & 1.499 & [0.718-3.132] & 0.2812 & & & - \\
\hline \multicolumn{7}{|c|}{ Lymphocyte Count } \\
\hline $\begin{array}{l}\geq 700 / \mu \mathrm{L} \\
<700 / \mu \mathrm{L}\end{array}$ & 1.297 & [0.684-2.462] & 0.4258 & & & - \\
\hline
\end{tabular}


Table 3: Prognostic parameters on univariate and multivariate analysis for lung cancer patients (Continued)

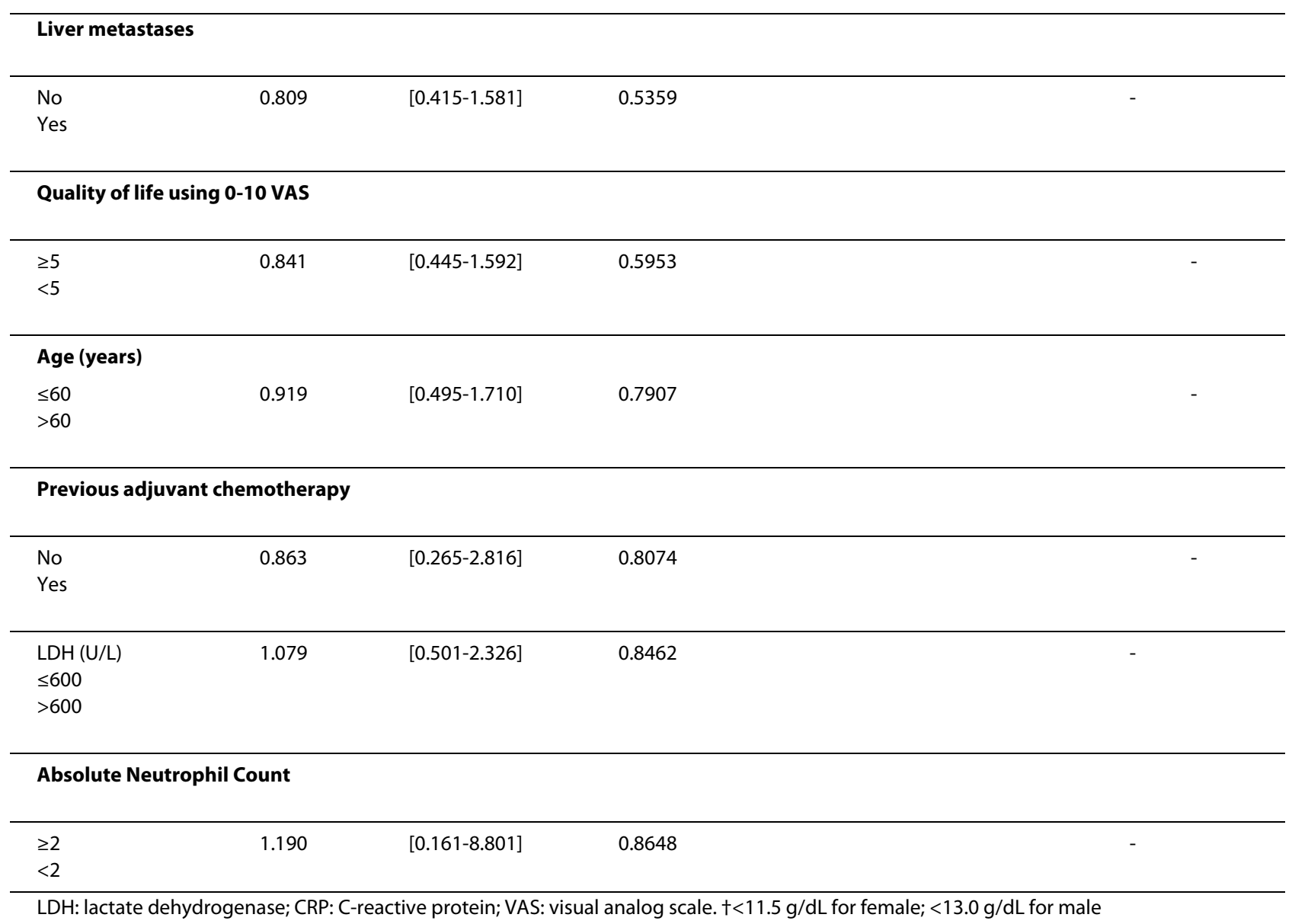

For example, a series of 14 South Western Oncology Group (SWOG) trials, where 2531 patients with inoperable lung cancer were recruited during 1974 -1988 in order to investigate the impact that 50 prognostic factors had on survival, revealed that performance status, extent of disease, and weight loss were among the most important ones [11]. The median survival was found to be 6.7 months in PS 0,1 patients and 3. 8 months in PS 2 patients.

For patients with good PS, pretreatment Hb level >= 11 $\mathrm{g} / \mathrm{dl}$, normal LDH, calcium levels and a single metastatic site were favorable factors [11]. A recursive partitioning and amalgamation analysis showed that the best survival occurred in patients with good PS who had Hb levels >= $11 \mathrm{~g} / \mathrm{dl}$ and were older than 47 years.

Further more, the Eastern Cooperative Oncology Group (ECOG) in a five phase II/III trials performed on 1960 patients with advanced NSCLC during 1981-1994 and treated with cisplatin-based chemotherapy showed a median survival of 9.4 months for patients with PS0, 6.4 months for patients with PS1, and 3.3 months for patients with PS2, confirming once again the prognostic value of performance status [12,13].

In our study, performance status (PS) was also identified as independent prognostic factor. Median survival was 8 months in PS: $0-1$ patients, and 2 months in PS $>1$ patients.

Of all clinical and biological factors analyzed, PS and anemia were the only variables statistically significant in multivariate analysis. Neither presence of brain metastases nor a weight loss could predict patients' survival.

Anemia is commonly observed in lung cancer and is a major contributing factor to fatigue and decreased quality of life (QOL) [14]. Hemoglobin levels at the time of diagnosis can be considered as prognostic indicator in patients with NSCLC. Low hemoglobin levels are associated with decreased survival. The evaluation of this parameter can be used for a more accurate prognosis in this disease and a better adequacy of therapeutic indications [15].

Anemia is the most frequently observed haematological abnormality faced by cancer patients. 
Belbaraka et al. BMC Research Notes 2010, 3:164

Page 6 of 8

http://www.biomedcentral.com/1756-0500/3/164

Overall survival: ECOG Performance Status assessed by the physician

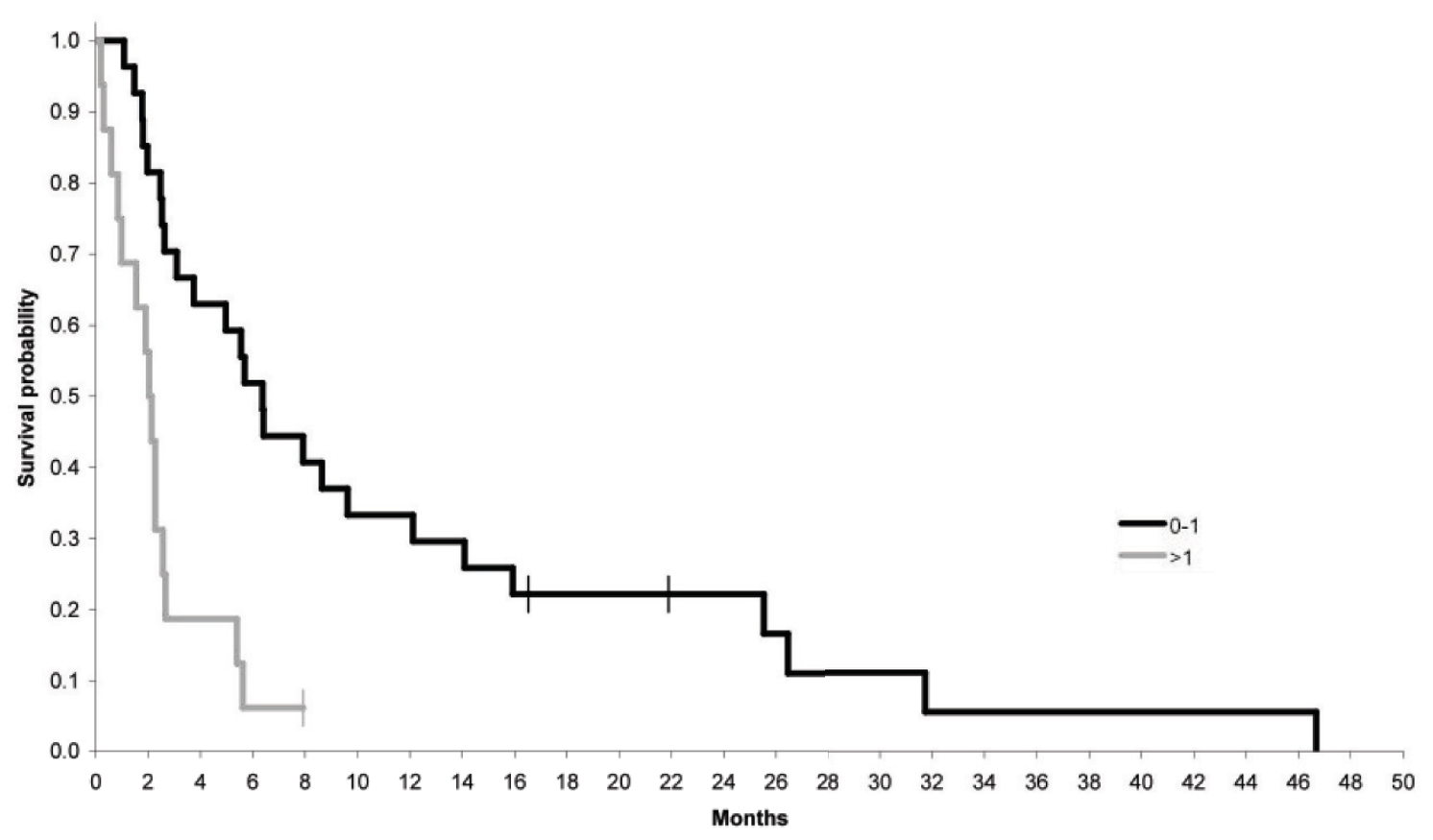

Figure 1 Relationship between performance status and overall survival

Overall survival: Hemoglobin

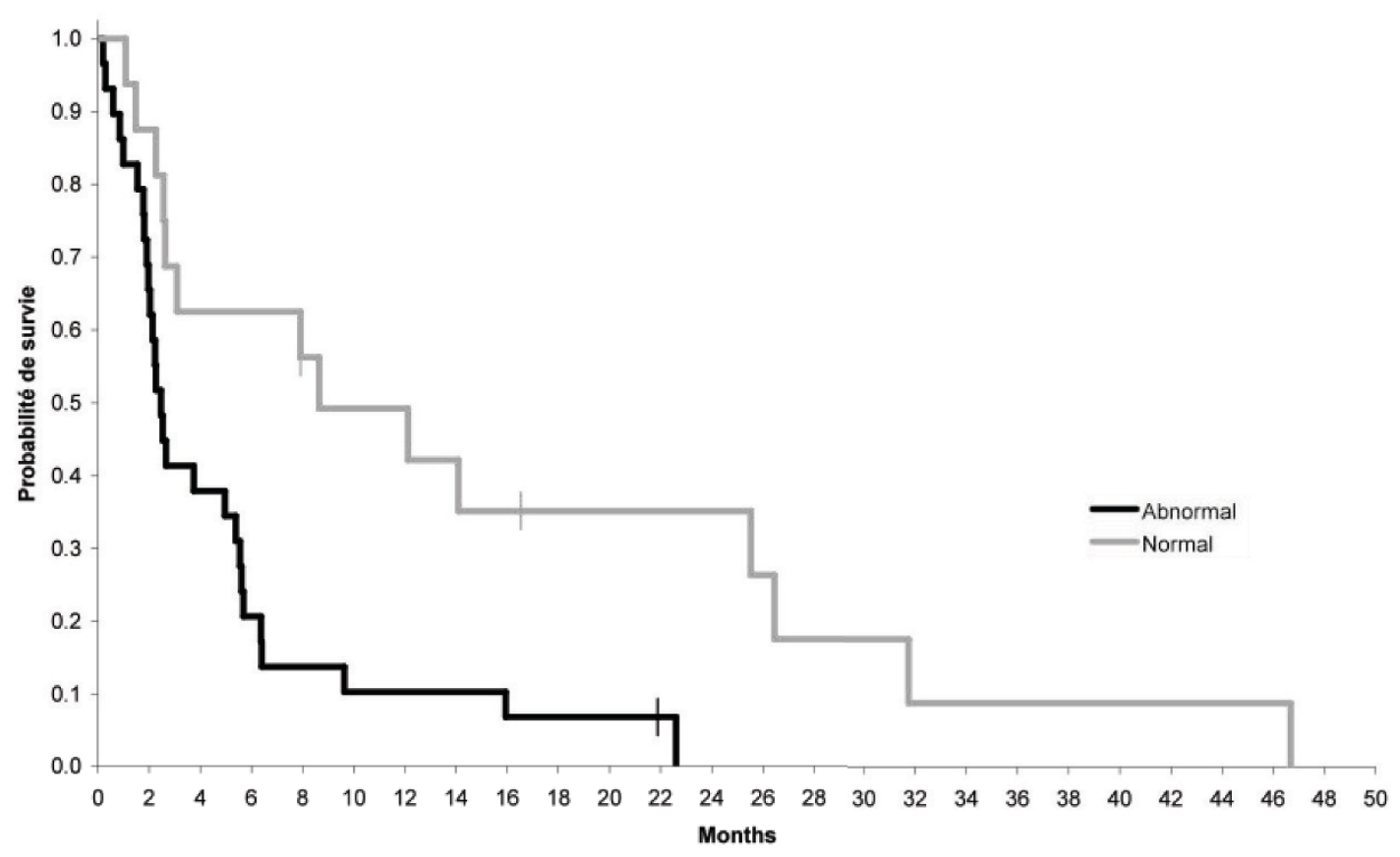

Figure 2 Relationship between hemoglobin level and overall survival

Yet, its association to tumour biology is not well under- 


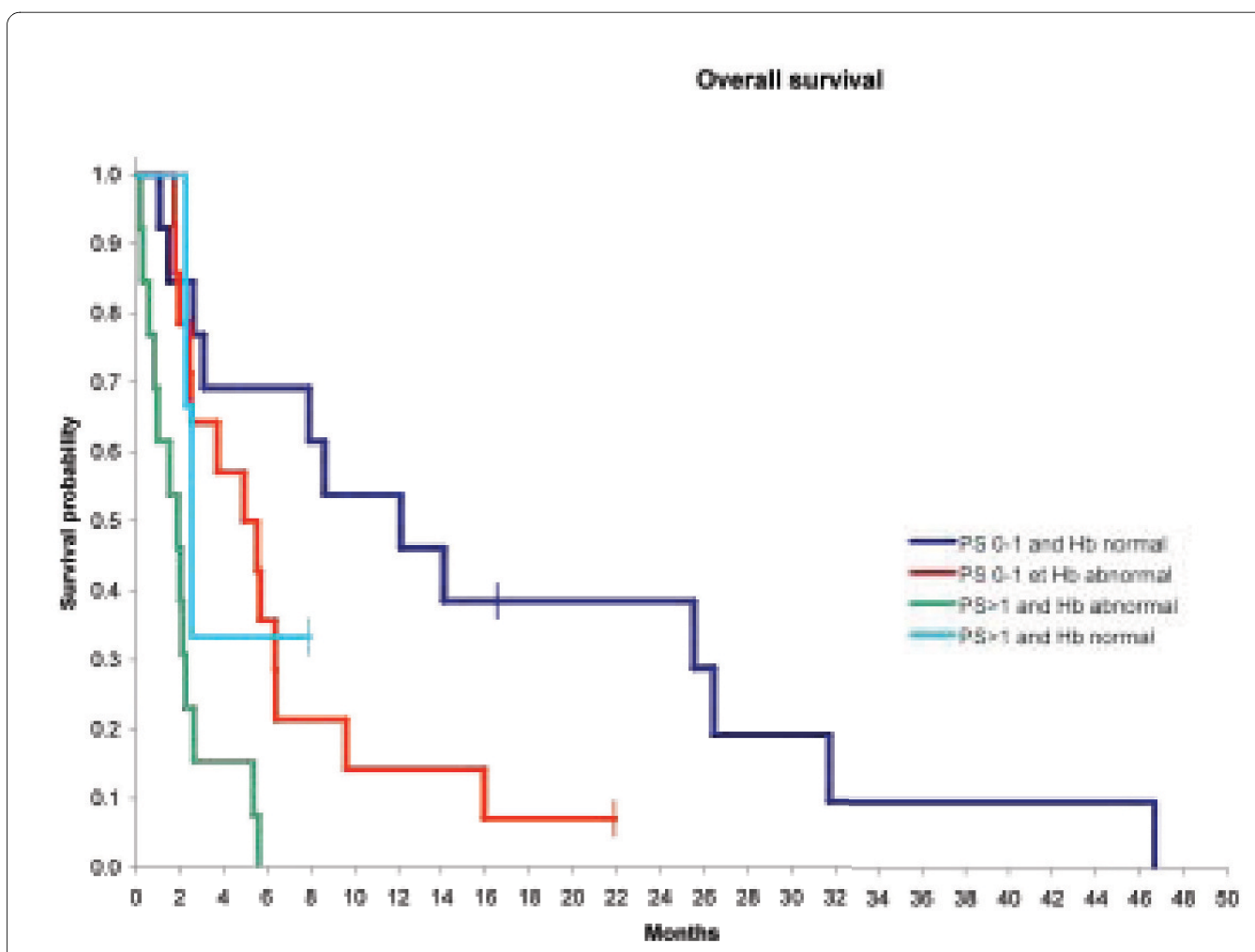

Figure 3 Results of analysis of 0,1 or 2 prognostic factors with Kaplan-Meier overall survival analysis

stood. Several recent retrospective clinical studies showed that anemia is not only a negative prognostic factor but also, in some situations, a negative predictive parameter in chemotherapy-treated patients with solid tumours or haematological malignancies. These include lymphomas, leukaemias, non-small-cell lung cancer, ovarian cancer, cervical cancer, urothelial and renal cancers, and head and neck carcinoma [16,17].

The treatment of anemia in patients with cancer undergoing chemotherapy may improve outcome in terms of both response rate to treatment and survival.

Several clinical signs have been shown to be prognostically important in terminally ill cancer patients [18]. Symptoms like anorexia-cachexia syndrome or delirium and cognitive impairment are related with end-of-life and therefore are not relevant for patients undergoing chemotherapy. Other clinical signs, such as dyspnea and weight loss, have also proven effective to predict life expectancy. When choosing between chemotherapy and supportive care alone, patients' preferences should be taken into account, considering that most patients are willing to accept chemotherapy for a very small chance of benefit.

\section{Conclusion}

The decision to stop chemotherapy is one of the hardest challenges in oncology practice. Chemotherapy remains widely prescribed for terminally ill patients despite side effects and poor efficacy.

From our prospective observational study, we concluded that factors influencing survival on patients with Advanced Non-Small-Cell lung cancer, who had at least one line of chemotherapy treatment, were anemia and poor PS. Larger prospective studies seem necessary to develop prognostic test scores, adapted to NSCLC, which may help clinicians estimate patients' survival and make appropriate recommendations for active or supportive care to develop prognostic scores, which may help clinicians estimate patients' survival and make appropriate recommendations for active or supportive care.

\section{List of abbreviations}

NSCLC: non-small-cell lung cancer; PS: performance status; Hb: Heamoglobin;

\section{Competing interests}

The authors declare that they have no competing interests.

\section{Authors' contributions}

RB: Drafted the manuscript. OT: Participated in the design of the study, helped to draft the manuscript and review of the final manuscript and revising it critically for important intellectual content. OT and DP: Conceived of the study, and participated in its design and coordination. AB performed the statistical analysis. NI: Review of the final manuscript and revising it critically for important intellectual content. Ml: English Writing. All authors read and approved the final manuscript. 


\section{Acknowledgements}

This report has been presented as poster at the $1^{\text {st }}$ European Lung Cancer Conference, May 2009, Lugano, Switzerland.

\section{Author Details}

'Department of Medical Oncology, Centre Léon-Bérard, 28 Rue Laennec, Lyon69008, France, 2Department of Medical Oncology, National Institute of Oncology, Rabat-10000, Morocco, ${ }^{3}$ Department of Biostatistics, Centre LéonBérard, 28 Rue Laennec, Lyon-69008, France and ${ }^{4}$ Department of Microbiology, Moulay Ismail University, Meknes-50000, Morocco

Received: 16 March 2010 Accepted: 10 June 2010

Published: 10 June 2010

\section{References}

1. Glare P, Virik K, Jones M, Hudson M, Eychmuller S, Simes J: A systematic review of physicians' survival predictions in terminally ill cancer patients. BMJ 2003, 327:195-8.

2. Ray-Coquard I, Le Cesne A, Rubio MT, Mermet J, Maugard C, Ravaud A: Model for Severe Anemia Requiring Red Blood Cell Transfusion After Cytotoxic Conventional Chemotherapy Regimens. JCO 1999, 17:2840-6.

3. Ray-Coquard I, Ghesquière H, Bachelot T, Borg C, Biron P, Sebban C: Identification of patients at risk for early death after conventional chemotherapy in solid tumours and lymphomas. Br J Cancer 2001, 85:816-22.

4. Bachelot T, Ray-Coquard I, Catimel G, Ardiet C, Guastalla JP, Dumortier A: Multivariable analysis of prognostic factors for toxicity and survival for patients enrolled in phase I clinical trials. Ann Oncol 2000, 11:151-6.

5. Bachelot T, Ray-Coquard I, Mentetrier-Caux C, Rastkha M, Duk A, Blay JY: Prognostic value of serum levels of interleukin 6 and of serum and plasma levels of vascular endothelial growth factor in hormonerefractory metastatic breast cancer patients. Br J Cancer 2003, 88:1721-26.

6. Negrier S, Perol D, Menetrier-Caux C, Escudier B, Pallardy M, Ravaud A: Interleukin 6, Interleukin 10, and vascular endothelial growth factor in metastatic renal cell carcinoma: prognostic value of interleukin- 6 from the Groupe Français d'Immunotherapie. JCO 2004, 22:2371-8.

7. Borg C, Ray-Coquard I, Philip I, Clapisson G, Bendrisse-Vermard N, Menetrier-Caux C: CD4 lymphopenia as a risk factor for febrile neutropenia and early death after cytotoxic chemotherapy in adult patients with cancer. Cancer 2004, 101:2675-80.

8. Mountain CF: Revisions in the international System for staging Lung Cancer. Chest 1997, 111:1710-7.

9. Charloux A, Hedelin G, Dietemann A, Lfoundza T, Roeslin N, Pauli G: Prognostic value of histology in patients with non-small-cell lung cancer. Lung Cancer 1997, 17:123-34.

10. Stanley KE: Prognostic factors for survival in patients with inoperable lung cancer. J Natl Cancer Inst 1980, 65:25-32.

11. Albain KS, Crowley JJ, LeBlanc M, Livingston RB: Survival determinants in extensive stage non-small-cell lung cancer: the South West Oncology Group experience. JCO 1991, 9:1618-26.

12. Takigawa N, Segawa Y, Okahara M, Maeda Y, Takata I, Kataoka M: Prognostic factors for patients with Advanced non-small cell lung cancer: univariate and multivariate analyses including recursive partitioning and amalgamation. Lung Cancer 1996, 15:67-77.

13. Jiroutek $M$, Johnson D, Blum R, et al: Prognostic factors in advanced nonsmall-cell lung cancer: analysis of Eastern Cooperative Oncology Group trials from 1981-1992. Proc Am Soc Clin Oncol 1998, 17:461. (Abstr 1774)

14. Brundage MD, Davies D, Mackillop WJ: Prognostic factors in non-smallcell lung cancer: a decade of progress. Chest 2002, 122:1037-57.

15. Socinski MA, Morris DE, Masters GA, Lilenbaum R: Chemotherapeutic management of stage IV non-small-cell lung cancer American College of Chest Physicians. Chest 2003, 123:226S-43S.

16. Crawford J, Cella D, Cleeland CS, Cremieux PY, Demetri GD, Sarokhan BJ: Relationship between changes in hemoglobin level and quality of life during chemotherapy in anemic cancer patients receiving epoetin alfa therapy. Cancer 2002, 95:888-95.

17. Van Belle SJ, Cocquyt V: impact of haemoglobin levels in the outcome of cancers treated with chemotherapy. Oncol Hemato 2003, 47:1-11.
18. Morita Tatsuya, Tsunoda Junichi, Inoue Satoshi, Satoshi Chihara: Survival Prediction of Terminally III Cancer Patients by Clinical Symptoms: Development of a Simple Indicator. JJCO 1999, 29:156-9.

doi: $10.1186 / 1756-0500-3-164$

Cite this article as: Belbaraka et al., Factors of interrupting chemotherapy in patients with Advanced Non-Small-Cell Lung Cancer BMC Research Notes 2010, 3:164

\section{Submit your next manuscript to BioMed Central} and take full advantage of:

- Convenient online submission

- Thorough peer review

- No space constraints or color figure charges

- Immediate publication on acceptance

- Inclusion in PubMed, CAS, Scopus and Google Scholar

- Research which is freely available for redistribution
C BioMed Central 